\title{
PENGUJIAN KINERJA WEB SERVER POLINEMA MENGGUNAKAN ALAT UJI JMETER
}

\author{
Budi Harijanto ${ }^{1}$, Yuri Ariyanto ${ }^{2}$ \\ Jurusan Teknologi Informasi, Politeknik Negeri Malang \\ email: 'budi.harijanto@polinema.ac.id, ${ }^{2}$ yuri@polinema.ac.id
}

(Artikel diterima: Desember 2020, diterima untuk terbit: Januari 2021)

\begin{abstract}
Abstrak - Penelitian ini membahas kinerja we server Polinema. Masalahnya adalah belum diketahui kinerja dari web server Politeknik Negeri Malang (Polinema) http://polinema.ac.id, pada saat web server diakses oleh banyak pengguna. Tujuan agar dapat diketahui sejak dini berapa banyak pengguna yang dapat meng-akses web server Polinema dan rata-rata waktu kecepatan akses-nya dalam waktu bersamaan. Metode yang digunakan untuk mengukur kinerja dari web server Polinema adalah dengan alat uji menggunakan aplikasi Jmeter. Hasil dan pembahasan dari pengujian dengan simulasi 1000 pengguna melakukan akses secara bersamaan, yang mendapat akses ke web server Polinema hanya 690 pengguna dan sisanya gagal koneksi dengan waktu rata-rata koneksi 26 detik. Kesimpulan dengan asusmsi jumlah mahasiswa saat ini adalah 10.000 untuk melakukan kegiatan kuliah daring secara bersamaan, maka hanya $6.9 \%$ mahasiswa Polinema melakukan akses ke website Polinema secara bersamaan.
\end{abstract}

Kata kunci: kinerja, web server, jmeter, kecepatan akses

Abstract: This study discusses the performance of the Polinema we server. The problem is that the performance of the Malang State Polytechnic (Polinema) web server is not yet known http://polinema.ac.id, when the web server is accessed by many users. The goal is to know early on how many users can access the Polinema web server and the average access speed at the same time. The method used to measure the performance of the Polinema web server is a test tool using the Jmeter application. The results and discussion of the test with a simulation of 1000 users accessing simultaneously, only 690 users got access to the Polinema web server and the rest failed to connect with an average connection time of 26 seconds. The conclusion is that assuming the current number of students is 10,000 to conduct online lectures simultaneously, then only $6.9 \%$ of Polinema students access the Polinema website simultaneously.

Keywords: performance, web server, jmeter, speed access

\section{Pendahuluan}

Dunia jauh dari sempurna dan manusia sebagai pengguna melakukan banyak kesalahan. Beberapa kesalahan mungkin tidak penting tapi beberapa kesalahan bisa berbahaya dan bisa berakibat mahal. Bisa dibayangkan kesalahan atau kekurangan baru ditemukan di fase terakhir pengembangan sistem tentu saja kerugian yang ditimbulkan akan sangat besar.

Sebelum memeriksa atau menguji coba aplikasi atau software, bisa saja kesalahan atau kekurangan tersebut terletak di tempat yang tersembunyi. Juga sering kali ketika menguji aplikasi atau software tersebut tidak disadari kesalahan tersebut. Sebagai pembuat aplikasi atau sistem sering kali kita terlalu terbiasa hingga tidak melihat kekurangan tersebut. Penting diingat bahwa pengujian dengan menggunakan software atau pengujian secara otomatis juga menghindarkan kita dari kegagalan yang akan menimbulkan kerugian besar.

Pengujian web server dengan menggunakan software aplikasi berstandar seperti Jmeter diperlukan dalam rangka menghasilkan produk web server yang tidak hanya berkualitas tetapi juga aplikasi dengan biaya perawatan yang rendah (Jmeter open source). Selain itu juga memastikan software atau aplikasi yang kita kembangkan efektif.

Hasil yang diharapkan dari penelitian ini adalah diketahuinya kinerja dari website Politeknik Negeri Malang http://polinema.ac.id. Dengan demikian apabila ditemukan kinerja yang kurang, maka web server segera bisa di perbaiki. Pada akhirnya dengan tingkat kehandalan yang tinggi pada website Polinema, maka Polinema mampu meningkatkan pelayanan kepada mahasiswa.Website atau lazim disingkat web adalah halaman informasi yang disediakan melalui jalur internet sehingga bisa diakses di seluruh dunia selama terkoneksi dengan jaringan internet.

\section{Tinjauan Pustaka}

Website adalah salah satu alat komunikasi online yang menggunakan media internet dalam pendistribusiannya. Apapun bahasanya, yang pasti semua setuju bahwa website merupakan kumpulan halaman yang menampilkan informasi data teks, data gambar diam atau gerak, data animasi, suara, video dan atau gabungan dari semuanya, baik yang bersifat statis maupun dinamis yang membentuk satu rangkaian bangunan yang saling terkait dimana masing-masing dihubungkan dengan jaringan-jaringan halaman (hyperlink).

Secara terminologi website adalah kumpulan dari halaman-halaman situs, yang biasanya terangkum dalam sebuah domain atau subdomain, yang tempatnya berada di dalam World Wide Web (WWW) di Internet. WWW terdiri dari seluruh situs web yang tersedia kepada publik. Halamanhalaman sebuah situs web (web page) diakses dari sebuah URL yang menjadi "akar" ( root ), yang disebut homepage (halaman induk; sering diterjemahkan menjadi "beranda", "halaman muka"), URL ini mengatur web page untuk menjadi sebuah hirarki, meskipun hyperlink-hyperlink yang ada di halaman tersebut mengatur para pembaca dan memberitahu mereka susunan keseluruhan dan bagaimana arus informasi ini berjalan[9]-[10].

Sebuah Web page adalah dokumen yang ditulis dalam format HTML (Hyper Text Markup Language), yang hampir selalu bisa diakses melalui HTTP, yaitu protokol yang menyampaikan informasi dari server website untuk ditampilkan kepada para pemakai melalui web browser. Semua publikasi dari website-website tersebut dapat membentuk sebuah jaringan informasi yang sangat besar. 
Web page layaknya sebuah buku yang dapat menampung berbagai informasi tentang banyak hal baik bersifat komersil maupun non komersil. Melalui media web inilah seseorang dapat memberikan informasi tertentu kepada orang lain yang berada di seluruh dunia.

Website mulai dikenal di Indonesia sekitar tahun 1998, dimana hanya perusahaan besar saja yang mampu memilikinya. Pada saat itu, website merupakan sebuah teknologi yang cukup mahal untuk dimiliki. Sehingga banyak pengusaha maupun produsen mengurungkan niat mereka untuk dapat memiliki media promosi ini. Langkanya penyedia jasa pembuatan web yang menawarkan harga murah membuat keinginan perusahaan-perusahaan tersebut untuk memiliki sebuah website murah hanya menjadi sebuah mimpi[6] - [8].

Saat ini terdapat hampir milyaran halaman website yang memeriahkan dunia maya. Sebagian besar dari website tersebut adalah web komersial yang bersifat bisnis dan perdagangan. Rupanya media promosi dalam bentuk website sangat berperan penting dalam dunia usaha. Buktinya akhirakhir ini banyak pengusaha besar maupun kecil telah menggunakan website sebagai salah satu media promosi dalam memasarkan produk ataupun jasa. Fungsi website yang tidak hanya sebagai sarana promosi melainkan juga sebagai upaya untuk meningkatkan prestise (gengsi) dari suatu perusahaan telah membuat banyak pengusaha berani mengeluarkan biaya yang cukup tinggi untuk memiliki media online ini.

\section{Metode Penelitian}

\section{A. Metode}

Variabel pertama dalam pengukuran kinerja dari website Polinema ini adalah jumlah pengguna yang dapat mengakses. Pada Thread Group kita dapat mengatur berapa banyak pengguna yang mengakses akan kita simulasikan pada waktu yang bersamaan.

Variabel kedua dalam pengukuran kinerja dari website Polinema ini adalah lama waktu yang disediakan agar pengguna yang dapat mengakses. Pada Thread Group kita dapat mengatur berapa lama waktu yang disiapkan untuk semua pengguna yang mengakses website, yang disimulasikan pada waktu yang bersamaan.

Variabel ketiga dalam pengukuran kinerja dari website Polinema ini adalah jumlah perulangan melakukan pengujian dari beberapa titik lokasi. Pada Thread Group kita dapat mengatur jumlah perulangan melakukan pengujian untuk semua pengguna yang mengakses website, yang disimulasikan pada setting waktu yang sama.

Metodologi pengujian kinerja website Polinema ini adalah berdasarkan tahapan-tahapan sebagai berikut [1][2][3]:

1. Menjalankan JMeter

2. Menambahkan User Defined Variables: Di node ini kita akan menambahkan informasi global yang sering digunakan pada saat testing seperti informasi host dan port, Kemudian lakukan pengaturan User Defined Variables.

3. Menambahkan HTTP Header Manager: Setelah menambahkan node User Defined Variables, kita lanjutkan dengan menambahkan node HTTP Header Manager. Langkah-langkahnya sama seperti menambahkan node User Defined Variables, hanya saja yang dipilih adalah HTTP Header Manager. Di node ini kita akan menambahkan informasi apa saja yang dikirimkan JMeter ke HTTP request header.

4. Menambahkan HTTP Request Defaults: Langkah berikutnya adalah menambahkan node HTTP Request Defaults, caranya juga sama seperti sebelumnya hanya saja yang dipilih node HTTP Request Defaults. Di node ini kita cukup mengeset informasi nama server/ip address, port dan protocol.

5. Menambahkan Thread Group: Node ini digunakan untuk mengelompokan service yang akan di tes. Misal kita mempunyai melayani Mahasiswa dan Dosen, kedua service ini sebaiknya dibuatkan Thread Group masing-masing. Skenario kinerjance test ini bisa diganti-ganti nilainya sesuai kebutuhan.

6. Menambahkan HTTP Request: Setelah menentukan skenario kinerjance test, langkah berikutnya adalah menambahkan node HTTP Request. Di node inilah kita akan menentukan web service yang akan di tes. Misal web service mahasiswa mempunyai dua layanan yaitu GetByID dan GetByName. Nah dua layanan ini akan kita tambahkan sebagi bagian dari HTTP Request. Ulangi langkah sebelumnya untuk menambahkan service yang lain.

7. Menambahkan report untuk menampilkan hasil Kinerjance test: Ada beberapa format laporan yang digunakan untuk menampilkan hasil kinerjance test yaitu :

- View Results in Table

- View Results Tree

- Response Times Over Time

- Transactions per Second

- Statistical Aggregate Report

- Summary Report

8. Menjalankan Kinerjance test:

- Hasil Kinerjance Test

\section{B. Pengujian}

Pada Gambar 1 adalah gambar penyajian data yang diperoleh dari pengukuran kinerja website Polinema yang dilaksanakan di beberapa lokasi Polinema. Pada gambar tersebut diperlihatkan jumlah pengguna sebanyak 100 hingga 1000 yang mengakses pada waktu bersamaan.

Penjelasan dari Gambar 1 menunjukan bahwa website Politeknik Negeri Malang apabila diakses secara bersamaan oleh sebanyak 100 pengguna dan 200 pengguna, maka ratarata lama waktu mulai meminta akses hingga direspon oleh sever adalah sebesar $6500 \mathrm{~ms}$ atau 6.5 detik. Rata-rata apabila diakses hingga 1000 pengguna adalah $26500 \mathrm{~ms}$ atau 26,5 detik [4].

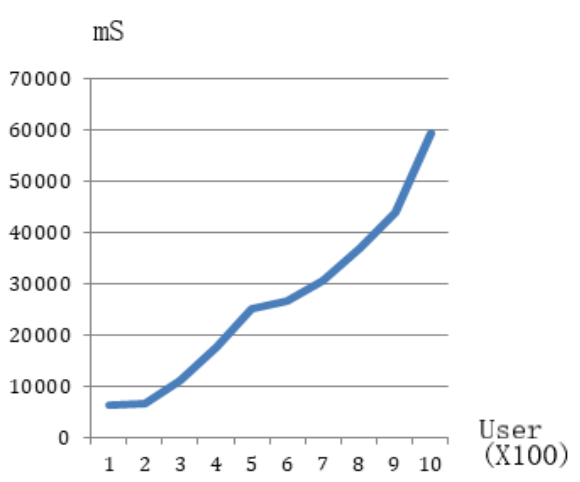

Gambar 1. Rata-rata waktu akses ke website Polinema 
Jurnal Teknik: Ilmu dan Aplikasi Vol. 02 No. 1, Januari 2021

Tabel 1. Skenario pengukuran kinerja website Polinema

\begin{tabular}{|l|l|l|}
\hline Skenario & $\begin{array}{l}\text { Jumlah } \\
\text { User }\end{array}$ & $\begin{array}{l}\text { Rata-rata } \\
\text { Latency (ms) }\end{array}$ \\
\hline Pengukuran ke - 1 & 100 & 6495.02 \\
\hline Pengukuran ke - 2 & 200 & 6577.04 \\
\hline Pengukuran ke - 3 & 300 & 11295.82 \\
\hline Pengukuran ke - 4 & 400 & 17722.9 \\
\hline Pengukuran ke - 5 & 500 & 25119.19 \\
\hline Pengukuran ke - 6 & 600 & 26663.00 \\
\hline Pengukuran ke - 7 & 700 & 30790.14 \\
\hline Pengukuran ke - 8 & 800 & 37082.05 \\
\hline Pengukuran ke - 9 & 900 & 43997.77 \\
\hline Pengukuran ke- 10 & 1000 & 59489.28 \\
\hline Rata-rata & & 26523.221 \\
\hline
\end{tabular}

Tabel 2. Hasil pengukuran ke-1 (Case 1) dengan pengguna sejumlah 1000

\begin{tabular}{|c|c|c|c|c|c|c|}
\hline $\begin{array}{c}\text { thread } \\
\text { Name }\end{array}$ & success & bytes & $\begin{array}{c}\text { all } \\
\text { Threads }\end{array}$ & $\begin{array}{c}\text { Late } \\
\text { ncy }\end{array}$ & $\begin{array}{c}\text { Conn } \\
\text { ect }\end{array}$ & Urutan \\
\hline $\begin{array}{c}\text { TG- } \\
\text { 1000UCase } \\
1-39\end{array}$ & TRUE & $\begin{array}{c}5677 \\
8\end{array}$ & 1000 & $\begin{array}{c}3498 \\
5\end{array}$ & $\begin{array}{c}2641 \\
3\end{array}$ & 1 \\
\hline $\begin{array}{c}\text { TG- } \\
\text { 1000UCase } \\
1-46 \\
\end{array}$ & TRUE & $\begin{array}{c}5677 \\
8\end{array}$ & 999 & $\begin{array}{c}3551 \\
3\end{array}$ & $\begin{array}{c}2617 \\
1\end{array}$ & 2 \\
\hline $\begin{array}{c}\text { TG- } \\
\text { 1000UCase } \\
1-189\end{array}$ & TRUE & $\begin{array}{c}5677 \\
8\end{array}$ & 998 & $\begin{array}{c}3551 \\
7\end{array}$ & $\begin{array}{c}2638 \\
7\end{array}$ & 3 \\
\hline $\begin{array}{c}\text { TG- } \\
\text { 1000UCase } \\
1-45 \\
\end{array}$ & TRUE & $\begin{array}{c}5677 \\
8\end{array}$ & 997 & $\begin{array}{c}3583 \\
5\end{array}$ & $\begin{array}{c}2634 \\
9\end{array}$ & 4 \\
\hline $\begin{array}{c}\text { TG- } \\
\text { 1000UCase } \\
1-259\end{array}$ & TRUE & $\begin{array}{c}5677 \\
8\end{array}$ & 996 & $\begin{array}{c}3597 \\
2\end{array}$ & $\begin{array}{c}2640 \\
4\end{array}$ & 5 \\
\hline $\begin{array}{c}\text { TG- } \\
\text { 1000UCase } \\
1-66\end{array}$ & TRUE & $\begin{array}{c}5677 \\
8\end{array}$ & 995 & $\begin{array}{c}3604 \\
2\end{array}$ & $\begin{array}{c}2642 \\
6\end{array}$ & 6 \\
\hline $\begin{array}{c}\text { TG- } \\
\text { 1000UCase } \\
1-203 \\
\end{array}$ & TRUE & $\begin{array}{c}5677 \\
8\end{array}$ & 994 & $\begin{array}{c}3603 \\
3\end{array}$ & $\begin{array}{c}2655 \\
0\end{array}$ & 7 \\
\hline $\begin{array}{c}\text { TG- } \\
\text { 1000UCase } \\
1-255 \\
\end{array}$ & TRUE & $\begin{array}{c}5677 \\
8\end{array}$ & 993 & $\begin{array}{c}3620 \\
4 \\
\end{array}$ & $\begin{array}{c}2620 \\
4 \\
\end{array}$ & 8 \\
\hline $\begin{array}{c}\text { TG- } \\
\text { 1000UCase } \\
1-139\end{array}$ & TRUE & $\begin{array}{c}5677 \\
8\end{array}$ & 992 & $\begin{array}{c}3621 \\
0\end{array}$ & $\begin{array}{c}2641 \\
7\end{array}$ & 9 \\
\hline $\begin{array}{c}\text { TG- } \\
\text { 1000UCase } \\
1-985 \\
\end{array}$ & TRUE & $\begin{array}{c}5677 \\
8\end{array}$ & 316 & $\begin{array}{c}5416 \\
0\end{array}$ & $\begin{array}{c}4801 \\
1\end{array}$ & 685 \\
\hline $\begin{array}{c}\text { TG- } \\
\text { 1000UCase } \\
1-419 \\
\end{array}$ & TRUE & $\begin{array}{c}5677 \\
8\end{array}$ & 315 & $\begin{array}{c}8117 \\
1 \\
\end{array}$ & $\begin{array}{c}7539 \\
9\end{array}$ & 686 \\
\hline $\begin{array}{c}\text { TG- } \\
\text { 1000UCase } \\
1-990 \\
\end{array}$ & TRUE & $\begin{array}{c}5677 \\
8 \\
\end{array}$ & 314 & $\begin{array}{c}5408 \\
0\end{array}$ & $\begin{array}{c}4842 \\
7 \\
\end{array}$ & 687 \\
\hline $\begin{array}{c}\text { TG- } \\
\text { 1000UCase } \\
1-927\end{array}$ & TRUE & $\begin{array}{c}5677 \\
8\end{array}$ & 313 & $\begin{array}{c}5585 \\
1\end{array}$ & $\begin{array}{c}4949 \\
2\end{array}$ & 688 \\
\hline $\begin{array}{c}\text { TG- } \\
\text { 1000UCase } \\
1-802 \\
\end{array}$ & FALSE & 3957 & 312 & 0 & $\begin{array}{c}9279 \\
8\end{array}$ & 689 \\
\hline $\begin{array}{c}\text { TG- } \\
\text { 1000UCase } \\
1-627 \\
\end{array}$ & FALSE & 3957 & 311 & 0 & $\begin{array}{c}9524 \\
5\end{array}$ & 690 \\
\hline $\begin{array}{c}\text { TG- } \\
\text { 1000UCase } \\
1-343\end{array}$ & FALSE & 3957 & 310 & 0 & $\begin{array}{c}9605 \\
6\end{array}$ & 691 \\
\hline $\begin{array}{c}\text { TG- } \\
\text { 1000UCase } \\
1-517\end{array}$ & FALSE & 3957 & 309 & 0 & $\begin{array}{c}9564 \\
5\end{array}$ & 692 \\
\hline $\begin{array}{c}\text { TG- } \\
\text { 1000UCase } \\
1-471 \\
\end{array}$ & FALSE & 3957 & 302 & 0 & $\begin{array}{c}9577 \\
4\end{array}$ & 699 \\
\hline
\end{tabular}

\begin{tabular}{|c|l|c|c|c|c|c|}
\hline $\begin{array}{c}\text { thread } \\
\text { Name }\end{array}$ & success & bytes & $\begin{array}{c}\text { all } \\
\text { Threads }\end{array}$ & $\begin{array}{c}\text { Late } \\
\text { ncy }\end{array}$ & $\begin{array}{c}\text { Conn } \\
\text { ect }\end{array}$ & Urutan \\
\hline $\begin{array}{c}\text { TG- } \\
1000 \text { UCase } \\
1-530\end{array}$ & FALSE & 3957 & 301 & 0 & $\begin{array}{c}9564 \\
1\end{array}$ & 700 \\
\hline $\begin{array}{c}\text { TG- } \\
1000 U \text { Case } \\
1-119\end{array}$ & FALSE & 3957 & 7 & 0 & $\begin{array}{c}1024 \\
28\end{array}$ & 994 \\
\hline $\begin{array}{c}\text { TG- } \\
1000 U C a s e \\
1-247\end{array}$ & FALSE & 3957 & 7 & 0 & $\begin{array}{c}1024 \\
56\end{array}$ & 995 \\
\hline $\begin{array}{c}\text { TG- } \\
1000 U C a s e \\
1-430\end{array}$ & FALSE & 3957 & 6 & 0 & $\begin{array}{c}1019 \\
87\end{array}$ & 996 \\
\hline $\begin{array}{c}\text { TG- } \\
1000 U C a s e \\
1-494\end{array}$ & FALSE & 3957 & 4 & 0 & $\begin{array}{c}1018 \\
68\end{array}$ & 997 \\
\hline $\begin{array}{c}\text { TG- } \\
1000 U C a s e \\
1-469\end{array}$ & FALSE & 3957 & 3 & 0 & $\begin{array}{c}1019 \\
31\end{array}$ & 998 \\
\hline $\begin{array}{c}\text { TG- } \\
1000 U C a s e \\
1-726\end{array}$ & FALSE & 3957 & 2 & 0 & $\begin{array}{c}1007 \\
34\end{array}$ & 999 \\
\hline $\begin{array}{c}\text { TG- } \\
1000 U C a s e \\
1-798\end{array}$ & FALSE & 3957 & 1 & 0 & $\begin{array}{c}1015 \\
90\end{array}$ & 1000 \\
\hline
\end{tabular}

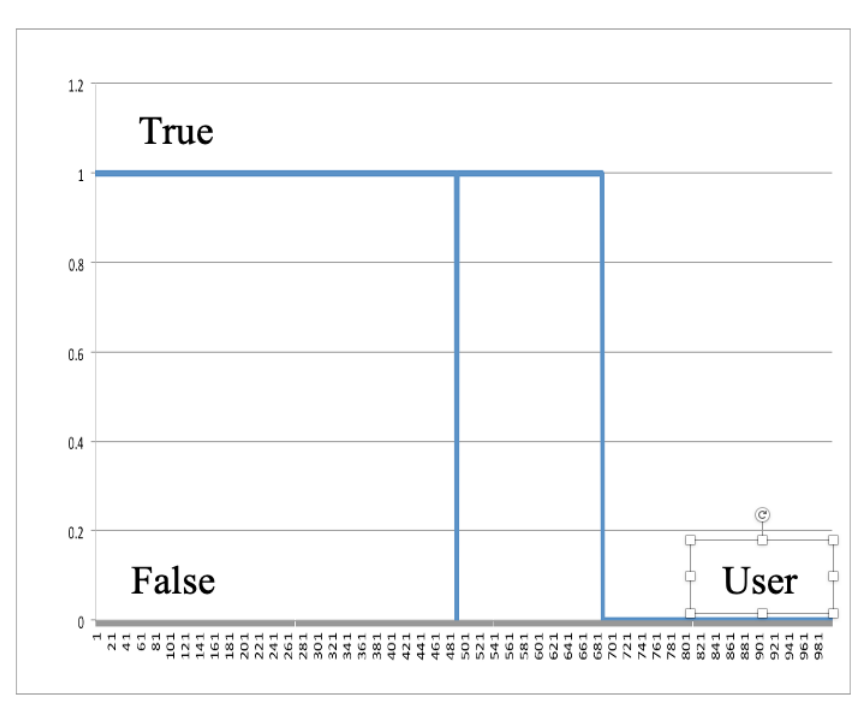

Gambar 2. Hasil Pengujian dengan 1000 pengguna (kegagalan koneksi)

Pengujian ke-1 hingga pengujian ke-10 dengan pengguna 100 hingga 1000 terjadi pengguna gagal koneksi pada pengujian mulai pengguna ke-689 dan seterusnya hingga ke 1000 seperti pada gambar 2. Sebagai tanda kalau setiap pengguna selalu dapat koneksi, maka ada tanda True, sebaliknya kalau tanda False berarti terjadi pengguna yang gagal koneksi[4].

\section{Hasil dan Pembahasan}

Analisa data berdasarkan jumlah pengguna, dengan asusmsi jumlah mahasiswa 10.000 dapat disimpulkan bahwa 690 pengguna itu setara dengan $690 / 10.000 * 100 \%=6.9 \%$ mahasiswa Polinema melakukan akses ke website Polinema secara bersamaan, dan $6.9 \%$ semuanya suskses terkoneksi dengan server Politeknik Negeri Malang http://polinema.ac.id. Dilihat dari sisi jumlah pengguna yang suskses terkoneksi dengan server, maka kinerja Politeknik Negeri Malang http://polinema.ac.id. terbukti lebih kurang $7 \%$.

Analisa data berdasarkan waktu respon server setelah menerima permintaan pengguna untuk melakukan koneksi, tercepat adalah $2351 \mathrm{mS}=2,3$ detik pada pengujian ke-1 pengguna 100. Sedangkan koneksi terlambat adalah 89.889 
$\mathrm{mS}=90$ detik pada pengujian ke-7 pengguna 700. Artinya tercepat waktu respon server setelah menerima permintaan pengguna untuk melakukan koneksi adalah lebih dari 2 detik dan terlambat waktu respon server setelah menerima permintaan pengguna untuk melakukan koneksi adalah 90 detik. Sedangkan rata-rata waktu respon server setelah menerima permintaan pengguna untuk melakukan koneksi adalah 6,5 detik pada pengujian 200 pengguna. Dengan jumlah pengguna 1000, maka kinerja website Polinema, ratarata waktu respon server setelah menerima permintaan pengguna untuk melakukan koneksi adalah 26,5 detik.

Analisa data berdasarkan jumlah perulangan melakukan pengujian sebanyak 10x pengujian, dan setiap pengujian ditingkatkan jumlah pengguna -nya 100 . Berdasarkan data pada gambar 1 waktu respon server setelah menerima permintaan pengguna untuk melakukan koneksi kenaikannya adalah linier setelah pengujian dengan 200 pengguna hingga 1000. Pada pengujian 100 pengguna hingga 200 waktu respon server setelah menerima permintaan pengguna untuk melakukan koneksi kenaikannya adalah flat atau datar pada 6,5 detik.

Tujuan pembahasan adalah sebagaia berikut ini:

1. Menjawab masalah penelitian: "Dunia jauh dari sempurna dan manusia melakukan banyak kesalahan. Beberapa kesalahan itu mungkin tidak penting tapi beberapa di antaranya berbahaya dan bisa berakibat mahal. Bayangkan seandainya kesalahan atau kekurangan baru ditemukan di fase terakhir dari pengembangan Website Polinema, tentu saja kerugian yang ditimbulkan akan sangat besar". Hasil dari penelitian, setelah dilakukan pengukuran kinerja dari Website Polinema dan terbukti kinerjanya baik hingga 690 pengguna. Sampai dengan pengujian 1000 pengguna, ditemukan koneksi yang putus antara Server Website Polinema dengan pengguna.

2. Menjawab bagaimana tujuan penelitian tercapai: Untuk menjawab tujuan penelitian pertama, yaitu "Mengukur tingkat kehandalan (kinerja) dari website Politeknik Negeri Malang http://polinema.ac.id". Sudah dilakuan dengan menghasilkan tabel 1 Skenario pengukuran kinerja website Polinema. Untuk menjawab tujuan penelitian kedua, yaitu "Memberikan penyajian informasi yang terkini atas kinerja website Polinema http://polinema.ac.id". Disajikan dalam gambar 2 Hasil Pengujian dengan 1000 pengguna (dalam satuan $\mathrm{mS}$ ) dengan tingkat kehandalan $6.9 \%$ dengan asumsi jumlah seluruh mahasiswa yang meng-akses 10.000 orang

3. Menjawab menafsirkan temuan-temuan penelitian: dari data Tabel 1 Skenario peng-ukuran kinerja Website Polinema http://polinema.ac.id. dengan pengguna sejumlah 200 waktu respond rata/flat 6,5 detik; dengan kenaikan jumlah pengguna hingga 1000, waktu respond naik linier hingga mencapai 60 detik.

\section{KESIMPULAN}

Hasil dari penelitian, setelah dilakukan pengukuran kinerja dari Website Politeknik Negeri Malang http://polinema.ac.id dan terbukti kinerjanya Sampai dengan pengujian 690 pengguna, tidak ditemukan koneksi yang putus permanen antara Server Website Polinema dengan clientclient/penggunanya.

Waktu respon server setelah menerima permintaan pengguna untuk melakukan koneksi, tercepat adalah $2351 \mathrm{mS}$ atau 2,3 detik pada pengujian ke-1 100 pengguna. Sedangkan koneksi terlambat adalah $89.889 \mathrm{mS}=90$ detik pada pengujian dengan pengguna 700 . Artinya tercepat waktu respon server setelah menerima permintaan pengguna untuk melakukan koneksi adalah lebih dari 2 detik dan paling lambat waktu respon server setelah menerima permintaan pengguna untuk melakukan koneksi adalah 90 detik. Sedangkan rata-rata waktu respon server setelah menerima permintaan 1000 pengguna untuk melakukan koneksi adalah 26,5 detik. Ada temuan yang menarik untuk jumlah pengguna $100-200$ dengan waktu respond rata/flat 6,5 detik.

\section{REFERENSI}

[1] Narinder Kaur, Kailash Bahl, "Kinerjance Testing Of Insititute Website Using Jmeter" IJISET - International Journal of Innovative Science, Engineering \& Technology, ISSN 2348 7968, Vol. 3 Issue 4, April 2016.

[2] Dr. Niranjanamurthy, Kiran Kumar "Comparative Study on Kinerjance Testing with Jmeter" International Journal of Advanced Research in Computer and Communication Engineering, ISSN (Online) 2278 - 1021, Vol. 5, Special Issue 2, October 2016

[3] Shagun Bhardwaj and Dr. Aman Kumar Sharma, "Kinerjance Testing Tools: A Comparative Analysis", International Journal of Engineering Technology, Management and Applied Sciences, ISSN 2349 - 4476, Volume 3 Issue 4 April 2015.

[4] Harijanto Budi, Ariyanto Yuri, 2020, Pengujian performa web Server menggunakan alat uji JMeter (Studi Kasus pada website Politeknik Negeri Malang http://polinema.ac.id) penelitian Reguler 2020

[5] T. Shinozaki, E. Kawai, S. Yamaguchi and H. Yamamoto, "Performance Anomalies of Advanced Web Server Architectures in Realistic Environments," 2006 8th International Conference Advanced Communication Technology, 2006, pp. 169-174,

[6] Abdul Kadir, 2009, Membuat Aplikasi Web dengan PHP + Database MySQL. Yogyakarta: Andi Offset.

[7] D. Arnaldy and T. S. Hati, "Performance Analysis of Reverse Proxy and Web Application Firewall with Telegram Bot as Attack Notification On Web Server," 2020 3rd International Conference on Computer and Informatics Engineering (IC2IE), 2020, pp. 455-459.

[8] X. Tian, H. Li and F. Liu, "Web Service Reliability Test Method Based on Log Analysis," 2017 IEEE International Conference on Software Quality, Reliability and Security Companion (QRS-C), 2017, pp. 195-199.

[9] L. P. Chitra and R. Satapathy, "Performance comparison and evaluation of Node.js and traditional web server (IIS)," 2017 International Conference on Algorithms, Methodology, Models and Applications in Emerging Technologies (ICAMMAET), 2017, pp. 1-4.

[10] F. Yudi Limpraptono, A. A. Putri Ratna and H. Sudibyo, "Remote laboratories multiuser based on embedded web server," 2012 9th International Conference on Remote Engineering and Virtual Instrumentation (REV), 2012, pp. 1-7.

[11] H. Zhong, L. Zhang and S. Khurshid, "TestSage: Regression Test Selection for Large-Scale Web Service Testing," 2019 12th IEEE Conference on Software Testing, Validation and Verification (ICST), 2019, pp. 430-440.

[12] H. Z. Abidin, F. Y. A. Rahman, I. M. Yassin and E. E. M Sayuti, "Development of a Local Web Server Linked to Malaysian Research and Education Network (MyREN)," 2009 Third International Conference on Next Generation Mobile Applications, Services and Technologies, 2009, pp. 515-519. 